\title{
THE RUPTURE OF ISOTHERMAL VERTICAL LIQUID FILMS
}

\author{
A. B. PONTER AND A. P. BOYES \\ Department of Chemical Engineering, University of New Brunswick, \\ Fredericton, N.B., Canada
}

Over the last decade a number of methods have been developed to predict when a stable film will break down into rivulets because of the influence of heat or mass transfer. For these conditions Marangoni effects are substantial. Hartley and Murgatroyd ${ }^{1)}$ and $\mathrm{McPherson}{ }^{2)}$ have set up energy balances which predict conditions for film rupture with reasonable accuracy when heat transfer occurs. In the analogous mass transfer situation using a similar analytical approach Ponter and Thornley3) have presented equations which predict conditions for which a stable dry patch is first formed. They also reported minimum wetting rates to maintain a stable film for water and ethanol-water systems on vertical surfaces of copper, stainless steel, Perspex and carbon and showed that the predicted and measured values were in very close agreement for all surfaces.

Analyses of film rupture for isothermal conditions have not been so successful as for the above mentioned cases where heat and mass transfer take place. The use of the equations developed by the afore-mentioned workers leads to deviations from the experimental values of minimum wetting rate of up to $1000 \%$. Little data have been presented in the literature for minimum wetting rates under isothermal conditions up to 1968, but two recent papers of importance have appeared, those of Iijima and Kuzuoka ${ }^{4}$ ) and Hobler and Czajka $^{5}$. Iijima and Kuzuoka ${ }^{4}$ have presented minimum wetting data for the systems methanol-water and glycerol-water representing a viscosity change of 1 to 12 centipoise and surface tensions of 72 to 26 dynes $/ \mathrm{cm}$. Their results were correlated by the empirical equation

$$
\frac{h \rho^{2}}{\mu^{4}}=0.11 \log \left(\frac{\sigma}{7.0}\right)
$$

where $h$ is the Nusselt film thickness. They further showed that the falling film was more stable for small pipe diameters than for large. At surface tensions below 40 dynes $/ \mathrm{cm}$, the minimum wetting rate was influenced by the pipe diameter, though Eq.(1) is applicable for flat plates and for pipe diameters greater than $3 \mathrm{cms}$.

Hobler and $\mathrm{Czajka}^{5)}$ measured the minimum wetting

\footnotetext{
* Received on May 31, 1971
}

rates of water and glycerol-water mixtures over a series of inclined planes of glass, aluminum, copper, stainless steel and a varnished surface and the results were correlated by the equation

$$
\frac{4 \Gamma}{\mu}=0.6153 W e_{z}^{.974}(1-\cos \theta)^{0.6}
$$

for $\quad 1.3<\frac{4 \Gamma}{\mu}<1000$

where $W e_{2}=$ Weber Number.

Also, a small amount of isothermal data for water films was presented by Norman and McIntyre ${ }^{6)}$ and is given in Table $\mathbf{1}$.

The two experimental procedures of Iijima and Kuzuoka ${ }^{4)}$ and Hobler and Czajka ${ }^{5}$ describe basically different phenomena. In the former case minimum wetting rates are measured which are just sufficient to maintain a fully wetted surface whilst in the second situation wetting rates are determined which allow a liquid to wet a previously dry surface. It is obvious that the wetting rates in the latter case will be higher as the liquid does not have the advantage of flowing over a surface upon which an adsorbed layer of liquid exists. To estimate this effect the values of wetting rates by these workers were compared using the glycerol/water mixtures common to both investigations. A knowledge was required of the advancing and equilibrium contact angles measured on a vertical and horizontal glass surface, respectively, and these were experimentally determined and are presented in Fig. 1. For the conditions described by Hobler and Czajka $^{5}$ it was initially considered that the minimum wetting rate $\left(\Gamma_{H}\right)$ would be a function of $\left(1-\cos \theta_{A}\right)^{0.6}$ and for the work of Iijima and Kuzuoka ${ }^{4}\left(\Gamma_{I}\right)$ would

\begin{tabular}{|c|c|c|}
\hline $\begin{array}{c}\text { Water mean } \\
\text { temperature } \\
{\left[{ }^{\circ} \mathrm{C}\right]}\end{array}$ & $\begin{array}{l}\text { Surface } \\
\text { temperature } \\
{\left[{ }^{\circ} \mathrm{C}\right]}\end{array}$ & $\begin{array}{l}\text { M.W.R. } \\
{[\mathrm{lb} / \mathrm{ft} \mathrm{hr}]}\end{array}$ \\
\hline 30 & 30 & 25 \\
\hline 45 & 45 & 25 \\
\hline 60 & 60 & 25 \\
\hline 75 & 75 & 25 \\
\hline
\end{tabular}
be a function of $\left(1-\cos \theta_{E}\right)^{0.6}$ and that the ratio $\Gamma_{H} / \Gamma_{I}$ 


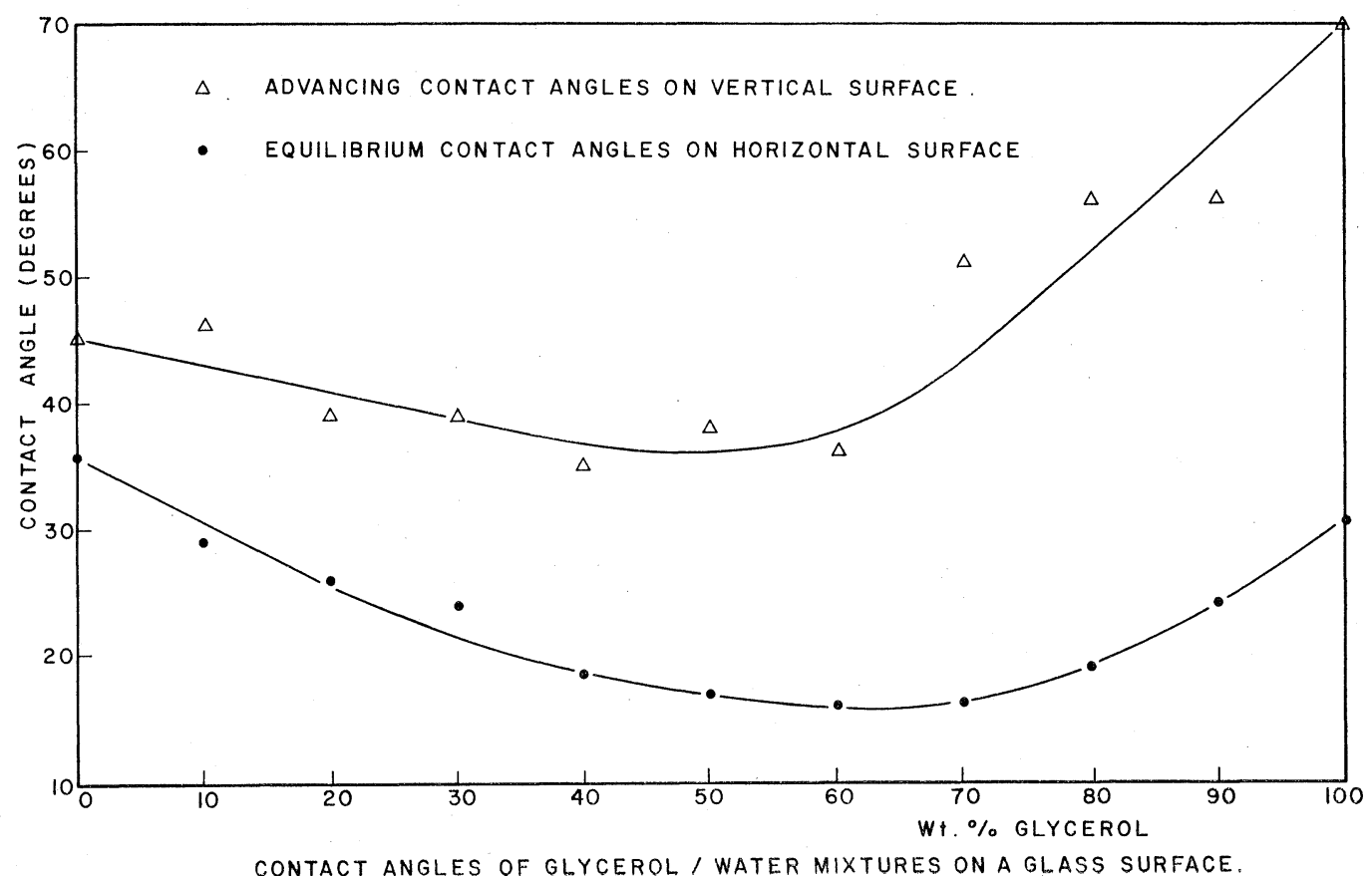

FIGURE I.

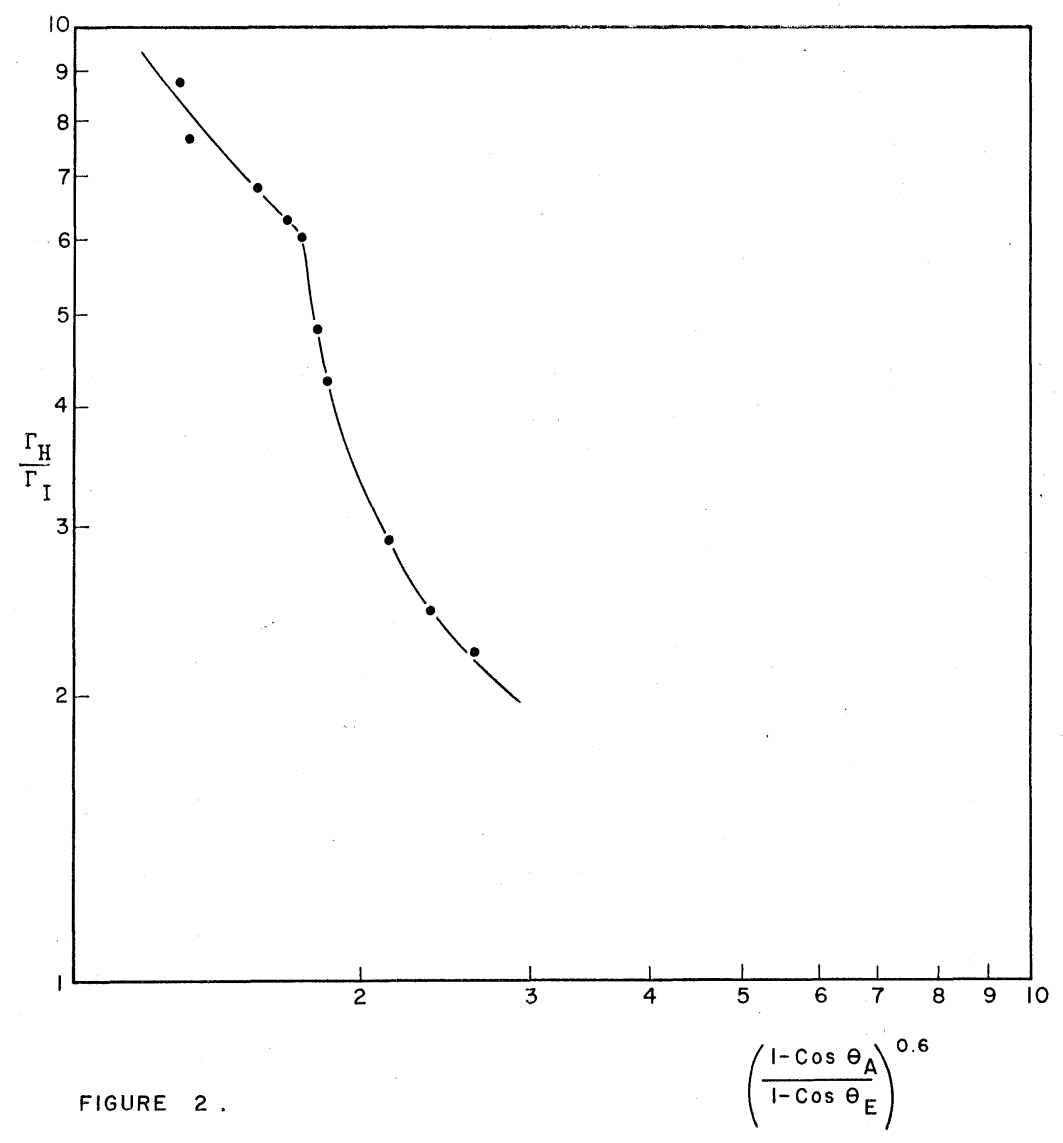



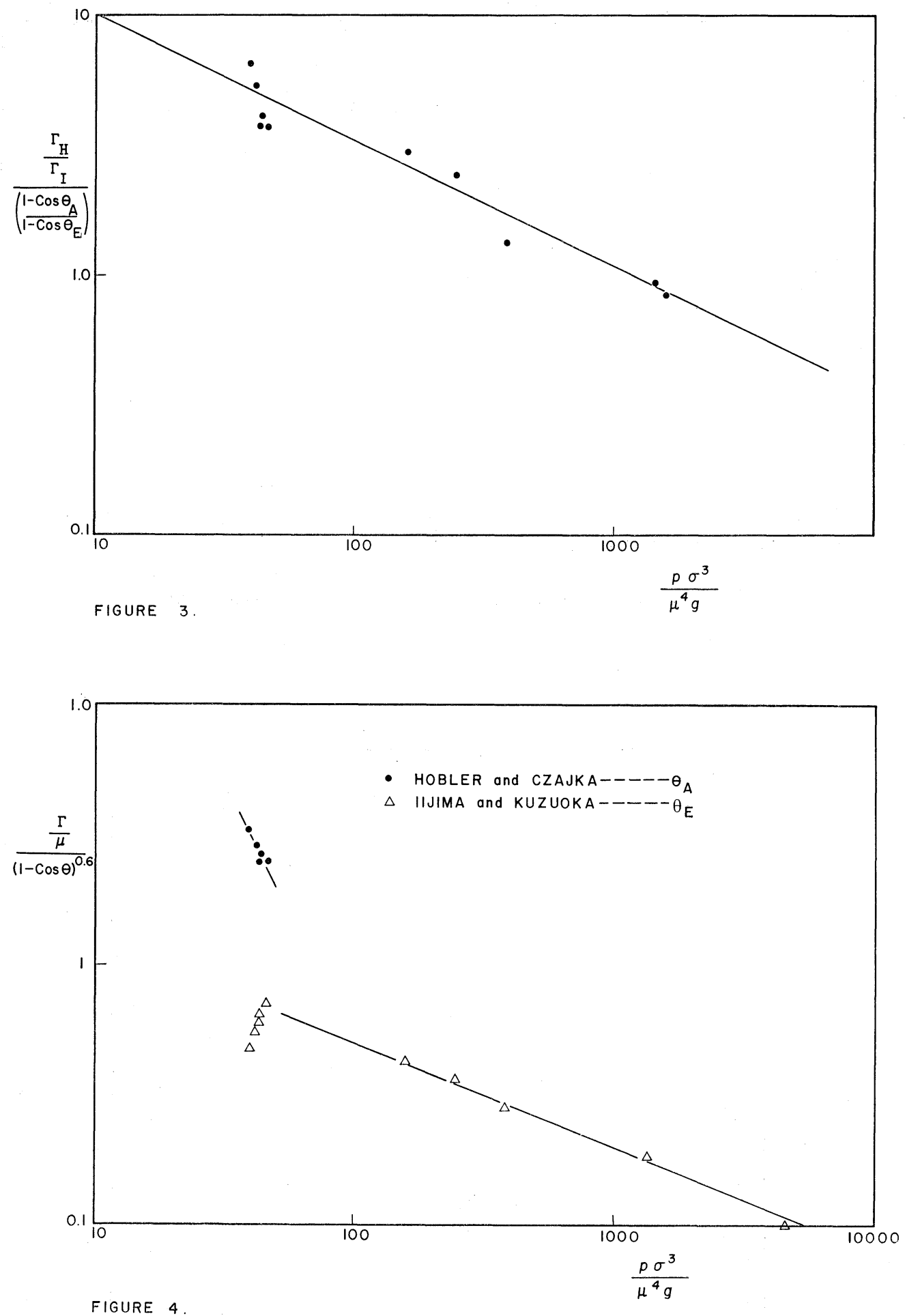

would be a function of $\frac{\rho \sigma^{3}}{\mu^{4} g}$ and $\left(\frac{1-\cos \theta_{A}}{1-\cos \theta_{E}}\right)^{0.6}$.

The corresponding plots are presented in Figs. 2 and 3. Fig. 3 indicates a negative power dependency for $\frac{\rho \sigma^{3}}{\mu^{4} g}$ to be 0.5 .

It is fundamentally wrong of course to assume that the hydrodynamics of flow at breakdown on a pipe and a flat plate are similar in form. In the former case the production of film rupture causes the following fluid to flow through the remaining unbroken film sector, causing it to increase in thickness and at the same time to reduce instabilities produced by pulsations. The hydrodynamics for the plate situation is more complex as the velocity profile across the plate is irregular because of the heterogeneous nature of the dry surface.

In Fig. 4 Hobler and Czajka's ${ }^{5)}$ data is presented in the form $(\Gamma / \mu) /\left(1-\cos \theta_{A}\right)^{0,6}$ versus $\left(\frac{\rho \sigma^{3}}{\mu^{4} g}\right)$. It 
should be noted here that the advancing contact angle is substituted for the equilibrium contact angle for the forementioned reasons. A similar graphical plot using the data of Iijima and Kuzuoka ${ }^{4}$ ) and employing the equilibrium contact angle is also included. A sharp discontinuity exists when an increase in viscosity occurs, i.e. where the surface forces play a less dominant role than the viscous forces.

This analysis demonstrates that the equations presented in the literature to date to predict breakdown on plates and tubes cannot be reconciled until a knowledge of the accompanying hydrodynamics is established, and that any analysis must account for the relative contributions made by the viscous and surface forces.

\author{
Nomenclature \\ $g \quad=$ force due to gravity \\ $h=$ Nusselt film thickness \\ $W e_{z}=$ Weber number \\ $\langle$ Greek symbols $\rangle$
}

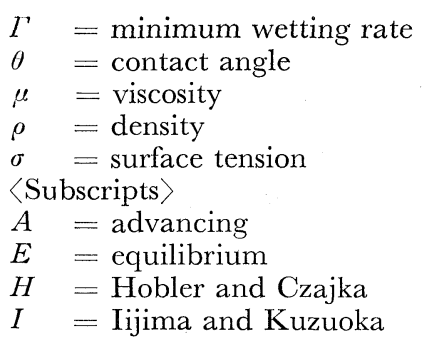

\section{Literature Cited}

1) Hartley, D. E. and N. Murgatroyd: Int. J. Heat Mass Transfer, 7, 1003 (1964)

2) McPherson, G. D.: Int. J. Heat Mass Transfer, 13, $1133(1970)$

3) Ponter, A. B. and P. G. Thornley: Chem. Proc. Eng., 8, $402(1964)$

4) Iijima, T. and T. Kuzuoka: Kagaku Kōgaku, 32, 52 (1968)

5) Hobler, T. and J. Czajka: Chemia Stosowana Ser B, 5, 169 (1968)

6) Norman, W. S. and V. McIntyre: Trans. Int. Chem. Engrs., 38, 301 (1960)

\title{
HEAT TRANSFER TO VESSEL WALL BY HELICAL RIBBON IMPELLER IN HIGHLY VISCOUS LIQUIDS*
}

\author{
SHINJI NAGATA, MASABUMI NISHIKAWA AND TAKASHI KAYAMA** \\ Department of Chemical Engineering, Kyoto University, Kyoto, Japan
}

\begin{abstract}
This paper is concerned with the correlation of heat transfer coefficients to heating and cooling jackets and also with the determination of an adequate value of the exponent to the viscosity correction term.
\end{abstract}

The correlation of heat transfer coefficients to the vessel wall $\left(h_{j}\right)$ agitated by a double helical ribbon impeller, shown in Fig. 1, is expressed as follows:

$$
\begin{aligned}
& \left(\frac{h_{j} D}{k}\right)=K\left(\frac{d^{2} n \rho}{\mu}\right)^{a}\left(\frac{C_{p} \mu}{k}\right)^{b}\left(\frac{\mu}{\mu_{w}}\right)^{c} \\
& N u=k R e^{a} \operatorname{Pr}^{b} V i s^{c}
\end{aligned}
$$

Mixing vessel is shown in Fig. 1, in which cooling water jackets and steam heated jackets are located side by side at $90^{\circ}$ intervals.

For pseudoplastic liquids, apparent viscosity around the impeller, $\mu_{a}$, is estimated as has been reported in power correlation ${ }^{1)}$ and was used in the evaluation of $R e, P r$ and $V i s$ terms.

In the laminar flow region, exponents $a$ and $b$ were determined as 1/3. As for $c$, various possibilities are presented, i.e. $0.14,0.18$ and 0.24 , etc. In case of using 0.14 for $c$ in Eq.(1), the correlated data are

* Received on August 30, 1971

** Satake Chem. Eng. Co., Ltd. scattered regularly, as shown in Fig. 2 curve (1), while by using 0.20 , the correlation is almost satisfactory, as shown by curve (3) in the laminar region. Thus the following relation is derived:

$$
\begin{aligned}
1<\operatorname{Re}<100 ;\left(\frac{h_{j} D}{k}\right) & =4.2\left(\frac{d^{2} n \rho}{\mu_{a}}\right)^{1 / 3}\left(\frac{C_{p} \mu_{a}}{k}\right)^{1 / 3}\left(\frac{\mu_{a}}{\mu_{a w}}\right)^{0.2} \\
& =4.2\left(\frac{d^{2} n \rho C_{p}}{k}\right)^{1 / 3}\left(\frac{\mu_{a}}{\mu_{a w}}\right)^{0.2}
\end{aligned}
$$

As shown by Eq.(2), the effect of viscosity is cancelled in the dimensionless equations except for the $V i$ s term. This may be explained by the fact that the thermal boundary layer on the heat transfer surfaces is thicker than the clearance between the vessel wall and the impeller, and the heat transfer thickness is always kept constant independently of viscosity.

In the region of $R e$ larger than $10^{3}$, the slope of the curve increases to $2 / 3$, which corresponds to the turbulent flow range, and 0.14 is recommended for $c$ rather than 0.2 .

Thus the following relation is obtained: 